\title{
Las canciones en la enseñanza-aprendizaje de ELE en la era digital
}

\author{
Rocío DíAz Bravo \\ London School of Economics (LSE) \\ University of Cambridge
}

Recibido: 10 octubre 2014 / Aceptado: 18 mayo 2015

ISBN: $1697-7467$

\begin{abstract}
RESUMEN: Las canciones constituyen un recurso didáctico muy eficaz en la enseñanzaaprendizaje de lenguas. Los docentes de ELE nos encontramos en un momento privilegiado para trabajar con canciones, debido a la confluencia de diversos factores: 1) éxito y difusión de la música en español, 2) creciente presencia de la lengua española en Internet, 3) fácil obtención de numerosos recursos y creación de una gran variedad de actividades interactivas, gracias a los avances tecnológicos de la era digital. Sin embargo, la mayoría de los materiales didácticos no aprovechan suficientemente el potencial de las TIC. Por ello, ofrezco sugerencias para la obtención de recursos legales y la creación de materiales didácticos digitales.

Palabras clave: Español como Lengua Extranjera (ELE), canciones, nuevas tecnologías o Tecnologías de la Información y la Comunicación (TIC), materiales didácticos digitales

\section{Songs in the Learning and Teaching of Spanish as a Foreign Language in the Digital Era}

\begin{abstract}
Songs are a very efficient resource for learning and teaching languages. It is an opportune time for teachers of Spanish to work with songs due to the convergence of a number of different factors: 1) the success and dissemination of songs in Spanish, 2) the increasing presence of Spanish on the Internet, 3) the easy accessibility to a number of resources and the creation of a great variety of activities, thanks to the technological advances of the digital era. However, most of the teaching resources do not take full advantage of ICT. For that reason, I offer some suggestions for obtaining legal online resources and creating digital resources.
\end{abstract}

Keywords: Spanish as a Foreign Language (SFL), songs, new technologies or Information Communication Technologies (ICT), digital teaching resources

En este artículo defiendo la importancia de las canciones como recurso didáctico en la enseñanza-aprendizaje de ELE en la era digital. A pesar de que nos encontramos en un momento privilegiado para trabajar con música en español (apartado 2), tras una breve revisión de materiales didácticos (apartado 3), podemos concluir que no se aprovecha suficientemente el potencial de las canciones ni de las nuevas tecnologías. Por ello, ofrezco sugerencias para la obtención de recursos legales y la creación de materiales didácticos digitales (apartado 4). 


\section{LAS CANCIONES: UN RECURSO DIDÁCTICO MUY EFICAZ EN LA ENSEÑANZA- APRENDIZAJE DE LENGUAS}

Aunque no existe un aparato teórico sólido que justifique la eficacia de la música y las canciones como recurso didáctico en la enseñanza-aprendizaje de lenguas, contamos con algunas aportaciones procedentes de investigadores de distintas disciplinas, con algunos estudios experimentales (Ludke, Ferreira y Overy, 2014), con iniciativas como el proyecto Comenius The European Music Portfolio: A creative Way into Languages -que pretende integrar actividades musicales en el aprendizaje de lenguas extranjeras en educación primaria-, así como con las observaciones, propuestas didácticas y experiencias prácticas, cada vez más numerosas, de profesores y de creadores de materiales didácticos.

Los investigadores de la psicología evolutiva y cognitiva, así como de la adquisición de lenguas, ponen de manifiesto que existe una relación directa entre el elemento musical y rítmico y el desarrollo y aprendizaje de lenguas, tanto primeras como segundas lenguas (Gil-Toresano, 2001: 40; Martínez Sallés, 2002: 4). La música de las canciones conecta con las zonas sensibles de nuestro cerebro, con nuestra memoria sensitiva, que se corresponde con nuestro hemisferio derecho, que es el encargado de gestionar todo el universo emocional: procesa el aspecto emocional del lenguaje y la música. Krashen observó un fenómeno que se produce en los aprendientes de segundas lenguas, consistente en que, poco después de haber hablado o mantenido una conversación en una lengua no nativa, queda como un eco de esa lengua, es decir, repasamos la conversación, los errores. Y esta repetición, que recuerda lo que Piaget había llamado lenguaje egocéntrico — es decir, el hecho de que los niños disfrutan oyéndose a sí mismos cuando hablan y repiten, sin tener en cuenta al destinatario- facilita el proceso de aprendizaje. Este fenómeno, según Murphey (1992: 773; 1994: 6-8) también ocurre con las canciones; se trata de lo que él denomina "the song stuck in my head phenomenon". Las canciones tienen la cualidad de quedarse "pegadas en nuestra cabeza" una vez que las escuchamos; se retienen fácilmente y actúan sobre la memoria. Las canciones, que se caracterizan por poseer numerosas repeticiones y por ser muy rítmicas, se pueden aprender y memorizar con gran facilidad. Y esta virtud de las canciones no debe desaprovecharse en el aprendizaje de lenguas. Las canciones conectan con nuestras emociones, poseen una enorme carga emocional y afectiva. La frecuente ausencia de referencias concretas a los personajes, espacio y tiempo en la letra de las canciones, hacen que cualquiera que las escucha pueda identificarse con ellas. Por otro lado, se ha demostrado que el balbuceo propio de los bebés y el lenguaje musical afectivo devuelto por los mayores — que en inglés recibe el nombre de motherese- es determinante en el desarrollo del lenguaje en niños pequeños. Murphey (1994: 7) llama a las canciones adolescent motherese, pues sustituyen ese discurso afectivo que todos necesitamos a lo largo de nuestra vida.

Maley (1987: 94) considera que las canciones y la poesía tienen una función "reaccional": hacen reaccionar al destinatario; no tienen un objetivo utilitario sino que su meta es hacer que la gente se sienta bien. La cuestión relativa a la reacción que provoca la música en la persona que la escucha ya había sido objeto de debate entre los filósofos de la Grecia clásica. En la civilización helénica, la música tenía una enorme importancia, y se le concedían muchas cualidades, entre ellas, terapéuticas. Entre las múltiples funciones atribuidas por los griegos a la música, conviene destacar las funciones catártica, hedonista y utilitarista, 
todas ellas interrelacionadas. El extraordinario poder que poseía la música (función catártica) hacía inevitable que esta se utilizara como un componente esencial de la educación (función utilitarista). Esta concepción educativa de la música no se contradice con la idea de que esta produce placer (función hedonista), sino que más bien, la incluye. Por tanto, ya desde la Grecia clásica -y debemos tener en cuenta la importancia del pensamiento griego en toda la cultura occidental-, se consideraba el uso de la música como un recurso de enorme valor pedagógico. Por otra parte, como ha señalado Martínez Sallés (2002: 6; 2006: 2) cabe destacar el hecho de que la música y las canciones forman parte de la tradición del aprendizaje por transmisión oral. Antes de la invención de la imprenta, e incluso después, la transmisión de conocimientos se hacía oralmente, por lo que había que recordarlos para volver a transmitirlos. En este proceso, la música ya estaba al servicio de la memoria.

Por otra parte, las canciones constituyen un recurso muy motivador y lúdico, así como un fenómeno cultural. Muchos investigadores y profesores coinciden en considerar la música y las canciones como uno de los recursos didácticos que más motiva a los alumnos, lo cual contribuye a crear un ambiente distendido y agradable en el aula de idiomas y una visión positiva de la enseñanza-aprendizaje de lenguas, tanto por parte de los docentes como del alumnado (Cf. Santos Asensi (1996: 367), Gil-Toresano (2001: 41), Fernández (2001: 197) y Blanco (2005: 1), entre otros). También existe acuerdo en concebirlas como un material muy lúdico. Según Gil-Toresano (2001: 42), se trata de un material que se presta al juego y a la manipulación. Santos Asensi (1997: 129) considera que la música constituye un fenómeno cultural. Es evidente el hecho de que la música y las canciones están en todos sitios, forman parte de nuestras vidas. La música (no solo como elemento sonoro sino también como fenómeno cultural) está presente en los bares, en las cafeterías, en los centros comerciales, en las tiendas, en el coche, en el cine, en el teatro, en los eventos deportivos, en los medios de comunicación (prensa, radio, televisión)... y, por supuesto, en Internet. Y esto debe aprovecharse en la enseñanza de lenguas.

\section{Un MOMENTO PRIVILEgIado PARA LOS PROFESORES DE ELE: ÉXITO Y DIFUSIÓN DE LA MÚSICA EN ESPAÑOL EN LA ACTUALIDAD Y DE LA LENGUA ESPAÑOLA EN INTERNET}

Cada vez es mayor la presencia de la música cantada en español, que cuenta, en palabras de Martínez Sallés (2002: 6), con una "presencia masiva en los medios de comunicación", incluida la Red. En el siglo xxi, la música española y en español goza de un gran éxito y difusión: además de la enorme influencia de la música española en Latinoamérica y viceversa, debemos destacar su difusión en países en los que el español no es lengua oficial, especialmente, en Norteamérica (Martínez García, 2006: 599), donde el español y el espanglish están creciendo notablemente. Este auge de la música en español en EEUU se ha visto reflejado en la creación de la Latin Academy Recording (1997) y en la puesta en marcha de los Grammy Latinos, concedidos anualmente desde el año 2000. Por otra parte, la RIAA (Recording Industry Association of America) concede desde 2001 los Premios de Oro y Platino de la música latina (en concreto, canciones o álbumes que poseen más del $50 \%$ por ciento en español). En el caso de la música española, según datos recientes de la 
Sociedad General de Autores y Editores (SGAE 2014) -que obtiene ingresos por la gestión de derechos de autor para sus asociados en 80 países diferentes ${ }^{1}$-, la difusión internacional del repertorio español, que está creciendo en los últimos años, ha alcanzado la cifra récord de recaudación internacional de los últimos 10 años en 2013.

Este éxito de la música en español coincide con la importante difusión del español en Internet, siendo la tercera lengua más usada en la Red después del inglés y el chino (Internet World Stats, 2012; Instituto Cervantes, 2012) y la cuarta lengua en lo que se refiere a demanda de documentos en Internet (Instituto Cervantes, 2012). Por tanto, los profesores de español nos encontramos ante un momento privilegiado para trabajar con canciones, tanto por la difusión de la música en español en la actualidad (lo cual suscita el interés y aumenta la motivación de nuestros alumnos), como por la facilidad para obtener numerosos recursos en español en la Red, crear materiales didácticos y compartirlos, gracias a la proliferación de aplicaciones, herramientas tecnológicas, sitios web, servicios legales en línea de descarga de música o para escuchar música o ver videoclips en streaming, etc.

\section{REVISIÓN DE MATERIALES DIDÁCTICOS}

La música y las canciones como recurso didáctico en la enseñanza de ELE están teniendo un interés creciente en la actualidad, lo cual se refleja en las cada vez más numerosas propuestas que encontramos tanto en manuales como en artículos, sitios web, etcétera. Sin embargo, el potencial didáctico que ofrece este material no suele aprovecharse lo suficientemente, reduciéndose su explotación en la mayoría de los casos a trabajar cuestiones gramaticales, y en menor medida, vocabulario, o incluso a mero adorno cultural dentro de una unidad didáctica; además, no se suelen aprovechar las numerosas opciones que ofrecen las nuevas tecnologías. No obstante, observamos cierto cambio en las propuestas más recientes.

\subsection{Materiales impresos}

Con respecto al uso de las canciones en los manuales de ELE, en los últimos años se introduce cada vez más el mundo musical, aunque con frecuencia las actividades se plantean como un adorno cultural que no tiene relación con el resto de la unidad didáctica ${ }^{2}$. Sin embargo, algunos manuales recientes ofrecen propuestas más innovadoras, como el caso de Bitácora 4 (Conejo, Garrido, Marín y Sans, 2014), que presenta una unidad didáctica dedicada íntegramente a canciones, en la que, entre otras actividades, se fomenta la práctica oral a partir de fragmentos de letras de diferentes canciones o proponiendo presentaciones orales en grupo sobre diferentes canciones para las que los alumnos deben buscar información y la propia canción (audio o vídeo) en Internet, así como crear y compartir una lista de reproducción.

\footnotetext{
${ }^{1}$ Véanse SGAE (2014) y Gutiérrez del Castillo (2006) para un análisis detallado de la difusión de la música española en el extranjero. Para un análisis de los iconos culturales hispanos en Internet (incluido los relativos a la música), véase Álvarez de Sotomayor, Soler Herreros y Noya (2006).

${ }^{2}$ Véase Blanco Fuentes (2005) para un análisis detallado del uso de canciones en los manuales de ELE y otros materiales impresos.
} 
Por otra parte, contamos con guías didácticas o libros de actividades dedicadas íntegramente a la explotación de las canciones para la enseñanza de ELE, entre las que podemos destacar Clase de Música, de Martínez Sallés (2012) ${ }^{3}$, de la editorial Difusión ${ }^{4}$. Consta de doce unidades didácticas basadas en la explotación de doce canciones reales para los niveles A1-C1 del MCER. Cada unidad está dividida en tres secciones: "antes de escuchar", "mientras escuchas" y "después de escuchar". Se trabajan no solo contenidos léxicos, gramaticales y socioculturales, sino que también se tienen en cuenta las funciones comunicativas y existe una integración de destrezas orales y escritas (incluidas la interacción oral y la mediación).

\subsection{Materiales en Internet}

Por otra parte, debe destacarse el número creciente de explotaciones didácticas de canciones para aprender español disponibles en Internet, tanto en blogs de profesores como en publicaciones académicas (Blanco Fuentes, 2005; Ruiz García, 2005) como, sobre todo, en sitios web específicos para profesores de ELE. No obstante, la mayoría de las propuestas son recursos tradicionales, normalmente en PDF, que se diferencian de los materiales impresos por incluir un enlace a un vídeo de la canción.

Con respecto a publicaciones académicas en PDF, existen algunas propuestas interesantes de libros o artículos en los que, de algún modo, se tiene en cuenta Internet, al menos como fuente de información. Es el caso de la propuesta de Blanco Fuentes (2005), que ofrece remisiones a páginas webs para ampliar información sobre un tema. Las actividades se centran especialmente en los contenidos gramaticales, culturales y léxicos. Martínez Sallés también tiene publicaciones con características similares con respecto a la integración de Internet en las tareas que propone. En "Navegar entre canciones" (2006) presenta propuestas de trabajo que se inscriben en el enfoque por tareas y que pretenden aprovechar el potencial cultural de las canciones. Se ofrecen enlaces a webs útiles para ampliar información sobre estos temas, así como a vídeos de YouTube y letras de canciones.

Existen sitios web de profesores de ELE con secciones dedicadas a actividades con canciones, lo cual demuestra el interés de este recurso. Entre ellos, deben destacarse FORMESPA y Todoele. En ambas encontramos muchas explotaciones didácticas sobre canciones que algunos profesores han publicado para compartir con la comunidad docente de ELE. La mayoría de las propuestas están en PDF e incluyen un enlace al audio o vídeo de la canción (generalmente en YouTube, aunque en muchos casos el vídeo ya no está disponible a través del enlace ofrecido). En Todoele (http://www.todoele.net/canciones/Cancion_list.asp) las explotaciones están organizadas por contenidos gramaticales y por temas. En FORMESPA (http://formespa.rediris.es/canciones/), cada explotación didáctica está acompañada de una breve descripción (están centradas principalmente en gramática, vocabulario y comprensión auditiva). Quisiera destacar la sección "Enseñando variedades dialectales con canciones": consta de actividades para trabajar la variación diatópica del español con cantantes de diversos puntos geográficos de los países hispanohablantes.

\footnotetext{
3 Véase también Martínez Sallés (2002).

${ }^{4}$ Otras guías didácticas son las de Santos Asensi (1997) -que sigue el enfoque por tareas y presenta actividades interesantes aunque no aprovecha el elemento sonoro de las canciones- y Corpas (1999) - que incluye un $\mathrm{CD}$ con once canciones elaboradas especialmente para alumnos de ELE de un nivel inicial, con objeto de trabajar contenidos lingüísticos (especialmente, gramaticales) y culturales.
} 
Entre los blogs, merece especial mención ProfeDeEle, que contiene una sección de canciones y que ha ganado el III Concurso de Blogs (2014) para la promoción del español y la cultura hispánica en la categoría de educación. Dicha sección contiene actividades de huecos o de opción múltiple con solución automática para realizar en línea-además, se ofrece una versión para imprimir. Las actividades están acompañadas de una breve descripción en la que se incluyen el nivel y los contenidos (gramática, léxico y comprensión auditiva). Se ofrecen hipervínculos para ampliar información sobre los cantantes, grupos o canciones, así como vídeos musicales. Cada explotación didáctica posee una Licencia Creative Commons del tipo Atribución-CompartirIgual.

Por otra parte, existen recursos en línea muy útiles y divertidos para aprender lenguas con canciones: Lyricsgaps, Lyricstraining y la aplicación LyricsTap (para uso individual y con fines educativos), todos ellos divididos en distintos niveles según la dificultad de la actividad (inicial, intermedio y avanzado/experto) y con una opción de karaoke. El primero, Lyricsgaps (http://www.lyricsgaps.com/), es un sitio web con ejercicios de huecos o de pestañas desplegables de opción múltiple. La letra de la canción siempre aparece junto a un videoclip; haciendo clic en cada palabra se accede a un diccionario bilingüe en 20 lenguas y existe la posibilidad de traducir ${ }^{5}$ la letra con tecnología de Microsoft Translator. Además, los profesores pueden crear sus propias actividades de manera muy fácil -marcando las palabras que aparecerán como huecos-, compartirlas con sus estudiantes y ver la puntuación que obtienen. Otra opción práctica es que todas las actividades tienen una versión imprimible en PDF, con las soluciones al final del ejercicio. El otro sitio web, Lyricstraining (http:// lyricstraining.com/), cuenta también con ejercicios de huecos pero más sofisticados, ya que los vídeos musicales están sincronizados con la letra de la canción, que se desplaza a medida que avanza la música. Su correspondiente aplicación, LyricsTap para smartphones y tabletas Android, posee una interfaz muy similar pero los ejercicios consisten en ordenar palabras.

Por tanto, observamos distintos grados de integración de las TIC en las actividades propuestas: materiales tradicionales en PDF que proponen algún enlace para ampliar información, inclusión de hipervínculos y de contenidos multimedia, actividades en línea con solución automática, cuyo texto puede incluso estar sincronizado con el vídeo musical.

\section{Obtención de Recursos y CReación de materiales didácticos para TRABAJAR CON CANCIONES EN LA ERA DIGITAL}

Internet permite el acceso a una enorme cantidad de información, así como cada vez más posibilidades de comunicación (tanto escrita como oral) y colaboración. La Red se ha convertido en la mayor fuente de información del mundo - información escrita, sonora, visual y audiovisual (multimedia) procedente de casi todos los países del mundo y elaborada por millones de personas-, lo cual proporciona usos muy prácticos en la enseñanza-aprendizaje de lenguas. Internet es una fuente de información actualizada en la que podemos acceder a diccionarios, bibliotecas, artículos y obras digitalizadas; leer la prensa, escuchar la radio, ver la televisión. Todo ello permite tener un contacto directo con la lengua española y con los

\footnotetext{
${ }^{5}$ Con las limitaciones y errores de la traducción automática.
} 
países hispanohablantes. La World Wide Web proporciona una infinidad de recursos útiles que pueden usarse como muestras de lengua reales para trabajar con música y canciones en clase de ELE: sitios web de cantantes y grupos, letras de canciones, listas de éxito, información del ámbito musical presente en textos periodísticos, etcétera. Además de textos escritos, podemos encontrar recursos en formato de audio y vídeo: videoclips, karaokes, emisoras de radio y canales de televisión sobre música, canciones para escuchar en streaming o para descargarlas, etc. La accesibilidad de numerosos recursos a través de Internet facilita enormemente la creación de materiales didácticos, que a su vez, pueden ser muy diversos gracias a los avances tecnológicos de la era digital.

\subsection{Obtención de recursos: letras de canciones, canciones y vídeos musicales}

Aunque son numerosos los recursos que podemos encontrar en Internet para trabajar con canciones y para la creación de materiales didácticos, es importante seleccionarlos teniendo en cuenta cuestiones legales de licencias de derechos de autor. Afortunadamente, cada vez es más fácil obtener recursos digitales (incluidas las canciones) de manera legal, gracias a los siguientes factores: la situación legal es cada vez más clara, existen numerosos servicios de calidad para el acceso autorizado a la música digital y los usuarios somos paulatinamente más conscientes sobre la importancia del uso legal de recursos de la $\operatorname{Red}^{6}$.

Entre los sitios web con letras de canciones, podemos destacar Metrolyrics, el primer (tanto cronológicamente como en popularidad) sitio web legal que ofrece letras de canciones y que cuenta con una base de datos de más de un millón de títulos ${ }^{7}$, además de con numerosos vídeos musicales, algunos de ellos con las letras de las canciones (no muy numerosos en español). Se trata de una web colaborativa en la que los usuarios pueden subir letras de canciones que faltan y modificarlas si tienen errores, siempre con la revisión por parte del equipo de Metrolyrics. No obstante, algunas letras de canciones presentan un problema de codificación de los caracteres especiales del español (vocales con tildes y la letra $\tilde{n}$ ). Para el caso del español quizá sea más apropiado usar una web (también legal) en dicha lengua (por lo que la interfaz también está en español), como Buluba, de PRISA radio -grupo radiofónico en español con presencia en doce países hispanohablantes-, que cuenta con un catálogo de más de 70000 canciones $^{8}$ de todos los tiempos, muchas de ellas en español.

Asimismo, es interesante mencionar servicios que ofrecen las letras de canciones sincronizadas con la música, entre los que destaca la pionera aplicación (legal) Tunewiki, disponible para smartphones, tabletas y ordenadores (que además permite la integración en Spotify). Es posible corregir las letras, en caso de que exista algún error, falta de ortografía o problema con la puntuación.

Con esta aplicación podemos cantar karaoke de forma muy sencilla: simplemente tenemos que buscar la canción o artista junto a la palabra "karaoke" en Spotify y abrir la aplicación Tunewiki para ver las letras sincronizadas. Existen otras opciones para cantar karaoke en español, tanto en línea -por ejemplo, Red Karaoke (con su correspondiente aplicación para smartphones y tabletas- como reproductores que se pueden instalar en el ordenador -entre ellos, vanBasco (compatible con Windows) o MidiCo (compatible con Mac).

\footnotetext{
${ }^{6}$ Cf. IFPI (2014), Instituto de Derecho de Autor (2014), Informa Telecoms \& Media (2013) y SGAE (2013).

${ }^{7}$ Según la información ofrecida en su sitio web: http://www.metrolyrics.com/about.html.

${ }^{8}$ Como explican en su web: http://www.prisaradio.com/es/pagina/buluba-com/.
} 
Por último, en lo que a letras de canciones se refiere, conviene resaltar la reciente proliferación de los lyric videos, una práctica cada vez más extendida entre los cantantes, que consiste en un vídeo musical que incluye la letra de la canción (muchos de ellos con diseños muy originales) y que se suele estrenar antes del videoclip oficial.

Con respecto a la obtención de canciones, existen numerosos servicios legales online para descargas de música o para escucharla en streaming, como iTunes, Deezer, Last.fm, Los40.com, MTV ..., por citar algunos de los existentes en España9. También es fácil encontrar vídeos musicales (tanto videoclips como lyric videos) en sitios web de calidad autorizados, como YouTube -el servicio musical más usado en el mundo, con presencia en casi la totalidad de los países- y Vevo -la plataforma líder en contenido vídeo-musical, cuyos vídeos también están disponibles en YouTube, y que se ha expandido a 13 países en $2014^{10}$. Para garantizar la calidad y legalidad de los vídeos en YouTube es importante tener en cuenta que el usuario que lo ha subido esté autorizado, como Vevo, la discográfica o el propio grupo musical. Si no, se corre el riesgo de que tenga propiedades alteradas -como la velocidad, con objeto de que no sea identificado y retirado de Internet-, y de que si ofrecemos el enlace a dicho vídeo, no perdure en el tiempo, pues depende del usuario que lo ha subido y además es probable que lo eliminen por cuestiones de derechos de autor. Esto mismo se puede aplicar al audio de las canciones y a sus letras, si no se trata de proveedores autorizados.

\subsection{Creación de materiales didácticos y niveles de explotación}

Gracias a Internet, el acceso a numerosos recursos para la creación de materiales didácticos de ELE basados en canciones es mucho más fácil y rápido. Quisiera insistir en la importancia de que se usen recursos autorizados, tanto por razones legales y éticas, como por motivos de calidad y de preservación. Además, las nuevas tecnologías multiplican las posibilidades de explotación que ya de por sí poseen las canciones como recurso didáctico. Existen numerosas herramientas para crear ejercicios de autoaprendizaje con solución automática y retroalimentación, como las herramientas de autor Hot Potatoes y Jclic, los cuestionarios de la plataforma educativa Moodle o la aplicación web Textivate. Permiten la elaboración de actividades de diversos tipos (huecos, ordenar, unir, opción múltiple, etc.) y la creación de materiales didácticos digitales con opciones multimedia. Son ideales para la práctica en casa de los alumnos o para la enseñanza virtual. En los mundos virtuales (Second Life, Open Sim), útiles para la práctica oral en línea, pueden diseñarse espacios apropiados para cantar karaoke, una actividad que suele gustar mucho a los alumnos-avatares. Otros recursos digitales útiles para la expresión oral, esta vez de forma asíncrona, son las pizarras de voz -Blackboard Collaborate, Voxopop- que permiten que los alumnos se graben a sí mismos y que el profesor pueda escucharlos individualmente. En definitiva, contamos con una gama de posibilidades para sustituir o complementar los recursos tradicionales con materiales interactivos, que podemos compartir con otros profesionales o alumnos. Para ello, es recomendable que asignemos licencias de Creative Commons ${ }^{11}$ a nuestros materiales didácticos.

\footnotetext{
${ }^{9}$ Véanse el Anuario de SGAE (2013: 18-22) y el informe de IFPI (2014: 44) para una lista exhaustiva de servicios legales de música digital en el panorama internacional.

${ }^{10} \mathrm{Cf}$. IFPI (2014: 20).

${ }^{11}$ Los diferentes tipos pueden consultarse en https://creativecommons.org/licenses/?lang=es_ES.
} 
En cuanto a la explotación de las canciones, por un lado, debemos destacar que las canciones son materiales muy flexibles: pueden usarse como elementos dentro de una unidad (incluso con una función decorativa) o también se puede diseñar una unidad didáctica o explotación basada en una o más canciones, cuyas actividades suelen estructurarse de la siguiente manera: antes, durante y después de la escucha. Además, una misma canción puede usarse para diferentes niveles y con diferentes propósitos. Los textos de las canciones también permiten la explotación por temáticas y de las destrezas orales (en el caso de la comprensión auditiva, tanto la escucha global como la escucha atenta) y escritas.

Por otro lado, en la enseñanza de lenguas, las canciones pueden usarse como texto, como pretexto e incluso como elemento de distensión (al inicio o final de la clase, o durante una pausa). La música como fenómeno cultural, el plano sonoro de las canciones y el elemento audiovisual de los videoclips pueden usarse como pretexto o como elemento motivador para actividades diversas sin necesidad de trabajar el texto de la canción, por ejemplo: describir lo que sugieren diversas melodías o voces, relacionarlas con un determinado género musical y una cultura, comentar fragmentos de un videoclip de manera oral o escrita, etc. La música y las canciones (incluyendo los vídeos musicales) pueden ser explotadas atendiendo a sus niveles músico-cultural (la música como fenómeno cultural), audiovisual, sonoro, y, sobre todo, textual (tanto texto oral como texto escrito).

El nivel textual es el nivel de explotación didáctica más importante, puesto que los textos de las canciones (tanto escuchados como leídos, es decir, tanto orales como escritos) son muestras de lengua reales, que permiten ser explotadas como cualquier otro texto, teniendo en cuenta las peculiaridades textuales de las canciones (su extensión, elementos estructurales, ritmo y temática). Los textos de canciones permiten la explotación de todos los niveles lingüísticos y de los diferentes tipos de cultura.

- Nivel fonético-fonológico. Para mejorar la percepción de determinados fonemas, podemos eliminar algunas grafías del texto de la canción para que los alumnos completen los huecos mientras escuchan, para lo que podemos servirnos de actividades de huecos con solución automática. Los juegos antes mencionados (Lyricsgaps, Lyricstraining) y escuchar la canción mientras que se lee la letra también ayudan a asimilar los sonidos de la lengua meta. Asimismo, las canciones pueden servir para percibir el acento de las palabras, siempre que este no esté alterado por motivos rítmicos. Para ello, podemos crear actividades de opción múltiple con las diferentes sílabas de las palabras. Además, cantar canciones es una práctica que puede mejorar la pronunciación de la lengua meta, aumentando la seguridad de los estudiantes. Para percibir el ritmo de una lengua, Gil (2007: 318) propone escuchar fragmentos de canciones infantiles en distintos idiomas.

- Nivel léxico-semántico. Es, junto con el nivel gramatical, el más explotado, pues son numerosas las propuestas de explotación del vocabulario o de los temas de una canción. Propongo la creación de actividades automáticas de relacionar palabras con significados o con imágenes ${ }^{12}$. Además, una práctica recomendable es ofrecer enlaces a diccionarios bilingües o monolingües e incluso a corpus lingüísticos (según el nivel), para que los alumnos puedan buscar las traducciones o definiciones de las palabras por sí mismos y aprender el

\footnotetext{
${ }^{12}$ Se pueden encontrar imágenes y fotos con licencias en el banco de imágenes y sonidos del Ministerio de Educación de España (http://recursostic.educacion.es/bancoimagenes/web/), en Free Images (http://www.freeimages.com/) y en Flickr (https://www.flickr.com/).
} 
significado en contexto. Si se quiere implicar más a los alumnos en el aprendizaje de su propio vocabulario, ellos mismos pueden crear tarjetas de memoria -conocidas como flashcards, se crean con aplicaciones web como Textivate o Cram- o un glosario colaborativo como el de la plataforma educativa Moodle.

- Nivel gramatical o morfosintáctico. En muchas ocasiones, los profesores escogemos determinadas canciones por sus contenidos gramaticales, como la abundancia de un determinado tiempo verbal. Podemos crear actividades de huecos o de opción múltiple -que, a su vez, pueden servir como actividad de escucha atenta- y actividades de unir elementos (por ejemplo: el determinante y el artículo para practicar el género, o un tiempo verbal con sus diferentes usos) o de ordenar palabras (teniendo en cuenta que el orden lógico puede estar alterado en las canciones). La actividad de opción múltiple puede realizarse a través de nubes de palabras ${ }^{13}$ para que el diseño sea más atractivo o incluso funcional.

- Nivel textual-discursivo. Otra posibilidad, menos explotada, es usar las canciones para trabajar la tipología textual, siempre teniendo en cuenta los elementos estructurales y las características formales de la canción: composición en verso que por lo general posee un estribillo y frecuentes repeticiones (las cuales, junto con la rima, ayudan a crear ritmo). Muchas de las canciones son composiciones líricas, pero también podemos encontrar canciones que incluyen diferentes tipos textuales, como textos narrativos, cuentos y cartas. Por ejemplo, canciones en las que hay narración son "19 días y 500 noches" de Sabina, "Marta, Sebas, Guille y los demás" de Amaral o "En el muelle de San Blas" de Maná. "Cuéntame un cuento" de Celtas Cortos es apropiada para conocer los elementos estructurales de un cuento. También de este grupo se puede aprovechar "20 de abril" como muestra de una carta informal. Una tarea que tenga como objetivo escribir un correo electrónico a un amigo o a un familiar, puede servirse de esta canción para identificar los distintos elementos de la carta, las construcciones y palabras propias del género epistolar, el registro coloquial. Para el día de San Valentín se puede aprovechar la canción "Carta de amor" de Juan Luis Guerra.

- Nivel sociolingüístico. Tanto los registros como las variedades dialectales son susceptibles de explotación didáctica, debido a la diversidad de canciones en español. Las variedades dialectales y diafásicas pueden ser tratadas tanto en aspectos fonológicos como morfosintácticos o léxicos. Las canciones son especialmente útiles para distinguir las diferencias de pronunciación de diversos acentos del mundo hispánico.

- Nivel textual-cultural. Por último, no podemos olvidar que los textos de las canciones sirven para aprender cultura: tanto la Cultura con mayúsculas como la cultura con minúscu$\operatorname{las}^{14}$. Son muchos los poemas musicados en nuestra lengua que gozan de gran popularidad, como el disco de Carlos Cano sobre Los sonetos del amor oscuro de Lorca; el poema de Alberti "Se equivocó la paloma", interpretado por Ana Belén o por Serrat, quien también canta la "Saeta" de Machado; "La canción del Pirata" de Espronceda que canta Radio Tarifa, etcétera. Con respecto a la cultura con minúscula, algunas canciones útiles pueden ser "En la Puerta del Sol" de Mecano (que trata sobre la Nochevieja en España), "Toca Madera" de Serrat (sobre las supersticiones), "Me gusta el fútbol” de Melendi, los villancicos.

\footnotetext{
${ }^{13}$ Algunas herramientas para crear nubes de palabras son Tagul o Tagxedo.

${ }^{14}$ Cf. Miquel y Sans (1992).
} 


\section{Conclusiones}

Tras este estudio de las canciones como recurso didáctico en la enseñanza-aprendizaje de ELE en la era digital, podemos extraer las siguientes conclusiones:

1. Las canciones constituyen un recurso eficaz en la enseñanza de lenguas por los siguientes motivos: su aspecto emocional y su función "reaccional"; son fáciles de memorizar; se insertan en la tradición de enseñanza occidental; aumentan la motivación tanto de alumnos como de profesores; tienen una fuerte presencia en la vida diaria; son muestras reales de lengua y cultura, por lo que permiten múltiples posibilidades de explotación didáctica (incluida la explotación de todos los niveles lingüísticos y la práctica de las destrezas orales y escritas) y un acercamiento a la cultura meta.

2. Los profesores de ELE nos encontramos en un momento privilegiado para trabajar con canciones, debido a la difusión y éxito de la música en español y de la lengua española en Internet, así como a los numerosos recursos y herramientas que ha puesto a nuestra disposición la era digital.

3. Cada vez son más numerosos los recursos didácticos con canciones para la enseñanza de ELE. Sin embargo, la mayoría de las explotaciones didácticas de las canciones solo se benefician de algunas de las ventajas que ofrecen las nuevas tecnologías, principalmente, de hipervínculos y materiales multimedia -enlaces a audio y vídeo de las canciones, en numerosos casos no actualizados o retirados de Internet por problemas de derechos de autor-, además de la colaboración entre profesores al compartir materiales didácticos y ponerlos a disposición de la comunidad docente. No obstante, las propuestas más recientes, aunque aún escasas, reflejan un cambio cualitativo en el aprovechamiento de las nuevas tecnologías.

4. La era digital ha propiciado el fácil y rápido acceso a numerosos recursos legales (textuales, auditivos y multimedia, frecuentemente enlazados a través de hipervínculos) que pueden usarse como materia prima para nuestras propias actividades, a materiales didácticos creados por otros profesionales que quieren compartirlos, y a herramientas computacionales que permiten variadas posibilidades de explotación didáctica (como actividades de solución automática y karaoke).

5. En definitiva, en la era digital podemos encontrar o crear materiales didácticos atractivos y motivadores para trabajar con canciones, que pueden usarse tanto en clase presencial, como para el autoaprendizaje o para la enseñanza virtual.

\section{REFERENCIAS BIBLIOGRÁFICAS}

Blanco Fuente, E. (2005). La canción en los manuales de E/LE: una propuesta didáctica, Redele, número 4, segundo semestre 2005, http://www.mecd.gob.es/redele/Biblioteca-Virtual/2005/ memoriaMaster/2-Semestre/BLANCO-F.html.

Conejo, E.; Garrido, P.; Martín Peris, E. y Sans, N. (2014). Bitácora 4. Barcelona: Difusión.

Corpas, J., (1999). Gente que canta: guía didáctica, Barcelona, Difusión.

Cueto Álvarez de Sotomayor, L.; Noya Miranda, J. y Soler Herreros, Ch. (2006). "El valor de los iconos culturales en Internet", en Instituto Cervantes, Enciclopedia del español en el mundo. Madrid: Plaza Janés, 823-847. 
Fernández, S. (2001). "Una canción”, en Fernández, S. (coord.), Tareas y proyectos en clase: Español Lengua Extranjera. Madrid: Edinumen.

Gil Fernández, J. (2007). Fonética para profesores de español: de la teoría a la práctica. Madrid: Arco/Libros.

Gil-Toresano Berges, M. (2001). "El uso de las canciones y la música en el desarrollo de la destreza de comprensión auditiva en el aula de E/LE", en Carabela 49. Madrid: SGEL, 39-54.

Gutiérrez del Castillo, R. (2006). "La difusión de la música española en el extranjero", en Instituto Cervantes, Enciclopedia del español en el mundo. Madrid: Plaza Janés, 585- 598.

Informa Telecoms \& Media (2013). "The international business newsletter of global music copyright", en Music \& Copyright, 20 de marzo de 2013, http://www.informatandm.com/ wp-content/uploads/2013/04/Music-Copyright-issue-478.pdf

International Federation of the Phonographic Industry (2014). IFPI Digital music report 2014, http://www.ifpi.org/downloads/Digital-Music-Report-2014.pdf.

Instituto de Derecho de Autor (2014). Guía legal y financiera de la música en España. Madrid: Fundación SGAE.

Ludke, K. M.; Ferreira, F. y Overy, K. (2014). "Singing can facilitate foreign language learning", en Memory and Cognition, Volume 42, Issue 1: 41-52.

Maley, A. (1987). "Poetry and song as effective language-learning activities", en Rivers, W. M. (ed.), Interactive Language Teaching. Cambridge: Cambridge University Press.

Martínez Sallés, M. (2002). Tareas que suenan bien: el uso de canciones en clase de ELE. Bruselas: Ministerio de Educación, Cultura y Deporte.

Martínez Sallés, M. (2006). "Navegar entre canciones", III Encuentro práctico de profesores de ELE, Würzburg, 19-20 de mayo de 2006, http://www.encuentro-practico.com/pdfw06/ canciones.pdf.

Martínez Sallés, M. (2012): Clase de música: actividades para el uso de canciones en la clase de español (A1-C1). Barcelona: Difusión.

Miquel, L. y Sans, N. (1992). "Lengua y cultura desde una perspectiva pragmática: algunos ejemplos aplicados al español", en Frecuencia L, 5: 3-14.

Murphey, T. (1992). "The Discourse of Pop Songs", en Tesol Qarterly vol. 26, no 4: 770-774.

Murphey, T. (19943 [1992]). Music and song. Oxford: Oxford University Press.

RIAA (2013). RIAA Updates Latin Gold \& Platinum Program, en Music Notes Blog, Recording Industry Association of America, http://www.riaa.com/goldandplatinum.php?content selector=historyx.

Ruiz García, R. (2005). De los baúles de Piquer a las maracas de Machín: la canción como contenido cultural en clase de ELE [Memoria de Máster, Universidad A. de Nebrija], en Redele, Número 3, primer semestre 2005, http://www.mecd.gob.es/redele/BibliotecaVirtual/2005/memoriaMaster/1-Semestre/RUIZ-G.html.

Santos Asensi, J. (1996). "Música española contemporánea en el aula de español”, en Rueda, M. y otros (eds.), Actuales tendencias en la enseñanza del español como lengua extranjera II: Actas del VI Congreso Internacional de ASELE. León: Universidad de León, 367-378.

Santos Asensi, J. (1997). M de música: unidades didácticas de español lengua extranjera. Barcelona: Difusión, Colección Tareas.

Sociedad General de Autores Españoles (2012, 2013). Anuario de las artes escénicas, musicales y audiovisuales, http://www.anuariossgae.com/home.html.

Sociedad General de Autores Españoles (2014). "SGAE incrementa un 7.5\% la recaudación internacional de sus autores", 20 de febrero de 2014, Sala de Prensa, http://prensa.sgae. es/notas-de-prensa/sgae-fundacion-sgae/1194-sgae-incrementa-un-75-la-recaudacion-internacional-de-sus-autores. 